\title{
Microphysical controls on the stratocumulus topped boundary-layer structure during VOCALS-REx
}

\author{
I. A. Boutle and S. J. Abel \\ Met Office, Exeter, UK \\ Correspondence to: I. A. Boutle (ian.boutle@metoffice.gov.uk) \\ Received: 28 November 2011 - Published in Atmos. Chem. Phys. Discuss.: 6 January 2012 \\ Revised: 6 March 2012 - Accepted: 7 March 2012 - Published: 20 March 2012
}

\begin{abstract}
Simulations at a range of resolutions are compared to observations from the South-East Pacific taken during VOCALS-REx. It is found that increased horizontal and vertical resolution make only small improvements to the bulk properties of the simulated cloud and drizzle, but the highest resolution simulation is able to realistically represent mesoscale features in the cloud field. We focus on the highest resolution simulation and demonstrate that a poor representation of the cloud microphysics results in excessive drizzle production. This promotes persistent drizzle induced decoupling of the boundary layer, giving a poor representation of the observed diurnal cycle of stratocumulus. Two simple changes to the microphysics scheme are implemented: a modified autoconversion parametrization and a new representation of the rain drop size distribution. This results in a more realistic simulation of boundary-layer diurnal decoupling, and improvements to the cloud liquid water path and surface drizzle rate.
\end{abstract}

\section{Introduction}

The representation of stratocumulus in numerical weather prediction (NWP) and climate models is a challenging problem. The formation, persistence and break-up of stratocumulus is dependent on the complex interaction of many different physical processes, most of which are themselves parametrized within general circulations models (GCMs). Typically, mixing from the atmospheric boundary layer transports moisture from the surface, especially in maritime regions. If this moisture is transported past the lifting condensation level, then a stratocumulus capped boundary layer can be formed. Once the cloud is formed, long-wave radiative cooling from the cloud top can drive negatively buoyant plumes which descend through the cloud layer, allowing the cloud to generate its own turbulent structure. This cloudtop radiative cooling can be enough to maintain the cloud layer even in the absence of surface-driven mixing, and if the turbulent eddies do not span the entire boundary-layer depth, the cloud layer is said to be decoupled from the surface (Nicholls, 1984). As the cloud layer thickens, microphysical processes will increase the size of the cloud liquid droplets, and the cloud will start to precipitate. This not only modifies the dynamics of the cloud layer, but also the subcloud layer as drizzle evaporation below cloud base acts to cool and moisten this layer. Finally, there is often a strong diurnal cycle in the cloud cover, driven both by direct shortwave heating of the cloud layer, but also by the possible stratification of the sub-cloud layer and the initiation of cumulus convection beneath the stratocumulus. Therefore to simulate stratocumulus realistically, GCMs must successfully couple the convection, boundary layer, microphysics and radiation parametrizations. Models are further hindered by the fact that thin stratocumulus often only occupies one or two vertical levels at the resolution of operational NWP and climate models.

Stratocumulus is of great interest though for both NWP and climate studies. Inaccurate forecasts of stratocumulus cloud cover can have a large effect on short range surface temperature forecasts, which are important to many customers. They are also of great importance to the climate system (Slingo, 1990) due to their radiative effects and potential feedback mechanisms in a perturbed climate. Boundarylayer clouds are also one of the largest uncertainties in current climate models (Bony and Dufresne, 2005), partly due to the physical processes already discussed, but also due to aerosol indirect effects (Twomey, 1974). 
Many previous studies have investigated the representation of stratocumulus in GCMs (Siebesma et al., 2004; McCaa and Bretherton, 2004; Wyant et al., 2010; Wang et al., 2011), with the quality of the cloud forecasts varying significantly between models. However, recent work by Stephens et al. (2010) has suggested a general trend of over-production of light drizzle in many GCMs. Bodas-Salcedo et al. (2008) investigated this in more detail for the Met Office Unified Model (MetUM), comparing observations from CloudSAT to the CFMIP Observational Simulator Package (COSP, BodasSalcedo et al., 2011) in the global NWP and climate versions of the MetUM. They noted that the model had two distinct regions of radar reflectivity, one representing the nondrizzling cloud mode and the other representing the drizzle mode. They showed that the CloudSAT observations did not show this bi-modal structure, and also that the intensity of the drizzle in the model was too high. It is not only simulations at the global scale that suffer from such problems, the high resolution versions of the MetUM also suffer from excessive drizzle (Wilkinson et al., 2012). Recently, Abel and Boutle (2012) have demonstrated a simple change to the rain drop size distribution that can be made to many microphysics schemes and significantly improves the representation of light rain.

It was with the general aim of improving understanding and modelling of stratocumulus that the VAMOS-OceanCloud-Atmosphere-Land Study (VOCALS, Wood et al., 2011) was instigated, with an intensive observation period during the Autumn of 2008 in the South-East Pacific. Many different observational platforms (satellite, ship, aircraft, radiosonde, buoy) were coordinated to provide a detailed description of the marine stratocumulus. Abel et al. (2010) provided an overview of the performance of the MetUM during October and November 2008, noting the over-production of drizzle as one of the more significant model errors to be addressed. This paper extends the work of Abel et al. (2010), focusing on a single case-study and comparing highresolution NWP simulations of the marine stratocumulus to observations. Section 2 discusses the models and observations we use and Sect. 3 gives a general overview of the case study. Section 4 gives a more detailed discussion of the boundary-layer structure and its representation in the model, with Sect. 5 discussing cloud and drizzle processes. Conclusions are then drawn in Sect. 6.

\section{Methodology}

We select a two-day period during 12 and 13 November 2008 for a modelling study of the South-East Pacific. This casestudy was chosen due to the presence of generally unbroken stratocumulus cloud cover and a high density of observations against which to validate the model. The Ronald $\mathrm{H}$. Brown research vessel was located near $75^{\circ} \mathrm{W}, 20^{\circ} \mathrm{S}$ during the two-day period, and this was chosen as the centre of our

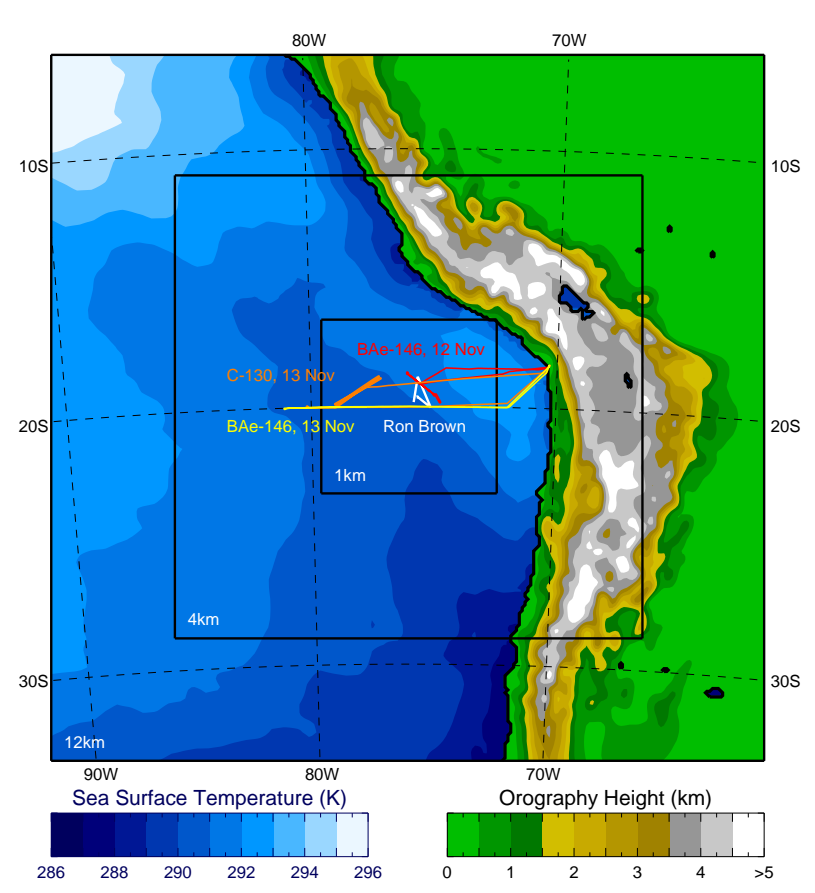

Fig. 1. Orography height and mean sea-surface temperature, with the horizontal coverage and resolution of the MetUM nested domains used in this study. Over-plotted are the tracks of the Ron Brown (white), BAe-146 (red and yellow) and C-130 (orange) during 12 and 13 November 2008.

modelling domain. There were also research flights by the FAAM BAe-146 on both days and by the NSF C-130 during the 13th.

The MetUM is used to produce a series of one-way nested simulations at increasing horizontal and vertical resolution in the South-East Pacific. The horizontal coverage and resolution of the nested domains is shown in Fig. 1. The driving model is the Global Atmosphere 3.0 configuration of the MetUM (GA3.0, Walters et al., 2011). This is the current operational configuration used for global NWP, seasonal and climate forecasts at the Met Office. The resolution used is $\mathrm{N} 320\left(0.5625^{\circ}\right.$ longitude by $0.375^{\circ}$ latitude) with 70 vertical levels below $80 \mathrm{~km}$, quadratically spaced to give more levels near the surface. This model is initialised from a Met Office global analysis at 00:00 UTC on 12 November 2008. To ensure that the large-scale state of the atmosphere and ocean surface remains as close as possible to the truth throughout the study period, the global model is re-initialised from a global analysis at 00:00 UTC on 13 November 2008.

The configuration of the higher resolution domains is chosen to follow that of the nested domains currently run over the UK for operational NWP, and Table 1 shows the main differences in their configuration from GA3.0. Some of the differences are genuinely required due to resolution differences, whilst others are due to the latest physics developments for GA3.0 not yet being present in the higher resolution models. 
Table 1. Table showing the differences between different resolution models.

\begin{tabular}{|c|c|c|c|c|}
\hline Model & Global & $12 \mathrm{~km}$ & $4 \mathrm{~km}$ & $1 \mathrm{~km}$ \\
\hline Resolution & $\begin{array}{l}\mathrm{N} 320,70 \text { levels, } 80 \mathrm{~km} \\
\text { top }\end{array}$ & $\begin{array}{l}12 \mathrm{~km}, 70 \text { levels, } 80 \mathrm{~km} \\
\text { top }\end{array}$ & $\begin{array}{l}4 \mathrm{~km}, 70 \text { levels, } 40 \mathrm{~km} \\
\text { top }\end{array}$ & $\begin{array}{l}1 \mathrm{~km}, 70 \text { levels, } 40 \mathrm{~km} \\
\text { top }\end{array}$ \\
\hline Timestep & $10 \mathrm{~min}$ & $3.33 \mathrm{~min}$ & $1.67 \mathrm{~min}$ & $0.5 \mathrm{~min}$ \\
\hline Convection & $\begin{array}{l}\text { GA3.0, based on } \\
\text { Gregory and Rowntree (1990) }\end{array}$ & As GA3.0 & $\begin{array}{l}\text { As GA3.0 but } \\
\text { with grid-box area } \\
\text { scaled CAPE closure }\end{array}$ & None \\
\hline Microphysics & $\begin{array}{l}\text { GA3.0, based on } \\
\text { Wilson and Ballard (1999) }\end{array}$ & As GA3.0 & $\begin{array}{l}\text { As GA3.0 but } \\
\text { with fixed } \\
N_{0}=8 \times 10^{6} \mathrm{~m}^{-3} \mathrm{~m}^{-1}\end{array}$ & As $4 \mathrm{~km}$ model \\
\hline Radiation & $\begin{array}{l}\text { GA3.0, based on } \\
\text { Edwards and Slingo (1996). } \\
3 \text { hourly calls with } 1 \text { hourly } \\
\text { cloud updates }\end{array}$ & $\begin{array}{l}\text { As GA3.0, but with } \\
\text { plane-parallel treatment } \\
\text { of sub-grid clouds. } 1 \mathrm{~h} \\
\text { call and } 20 \text { min cloud } \\
\text { updates }\end{array}$ & $\begin{array}{l}\text { As } 12 \mathrm{~km} \text { model. } \\
15 \text { and } 5 \text { min calls }\end{array}$ & $\begin{array}{l}\text { As } 12 \mathrm{~km} \text { model. } \\
5 \text { min calls }\end{array}$ \\
\hline Cloud & $\begin{array}{l}\text { PC2 (Wilson et al., 2008) as } \\
\text { in GA3.0 }\end{array}$ & $\begin{array}{l}\text { Smith (1990) with } \\
\text { cloud area parametriza- } \\
\text { tion discussed in } \\
\text { Boutle and Morcrette } \\
(2010) . \mathrm{RH}_{\text {crit }}=0.8 \\
\text { above } 900 \mathrm{~m} \text {, linearly } \\
\text { increasing to } 0.91 \text { at } \\
\text { surface. }\end{array}$ & As $12 \mathrm{~km}$ model & As $12 \mathrm{~km}$ model \\
\hline Horizontal diffusion & None & None & $\begin{array}{l}\nabla^{2} \text { with fixed } \\
K=8.5 \times 10^{3}\end{array}$ & $\begin{array}{l}\text { Smagorinsky (1963) } \\
\text { type scheme }\end{array}$ \\
\hline Vertical diffusion & $\begin{array}{l}\text { GA3.0, based on } \\
\text { Lock et al. (2000) }\end{array}$ & $\begin{array}{l}\text { As GA3.0, but without } \\
\text { updated cloud-top en- } \\
\text { trainment parametriza- } \\
\text { tion }\end{array}$ & As $12 \mathrm{~km}$ model & As $12 \mathrm{~km}$ model \\
\hline
\end{tabular}

The limited-area domains use a rotated-pole co-ordinate system, placing the equator at the centre of the domain allowing an approximately uniform grid.

The first nested domain has a horizontal grid-length of $12 \mathrm{~km}$. The main differences from GA3.0 are: the sub-grid cloud structure is not represented by the Monte-Carlo Independent Column Approximation, but rather by a simple plane-parallel method; the prognostic PC2 cloud scheme is replaced with the diagnostic scheme of Smith (1990); and the modifications to the cloud-top entrainment parametrization discussed in Walters et al. (2011) are not used. This nested domain is re-configured from the global model at 01:00 UTC on 12 November 2008 (i.e. $T+1$ ) and thereafter is freerunning throughout the case-study period, forced only at the boundaries by the global model.

The second nested domain has a horizontal grid-length of $4 \mathrm{~km}$. At this grid-length, convection is starting to be resolved on the model grid, so the convection scheme uses a modified convective available potential energy (CAPE) closure (Lean et al., 2008). The CAPE closure timescale is in- creased at low CAPE values, effectively turning down the convection parametrization and allowing convection to be dealt with by the resolved model dynamics. The only other scientific differences are the size spectra for rain, which uses a fixed intercept parameter $N_{0}=8 \times 10^{6} \mathrm{~m}^{-3} \mathrm{~m}^{-1}$ rather than the variable $N_{0}$ used in the lower resolution models, and some simple horizontal diffusion is implemented. This model also has an enhanced vertical level set, still with 70 levels, but now with a $40 \mathrm{~km}$ top, significantly increasing the tropospheric resolution. Similar to the $12 \mathrm{~km}$ simulation, this resolution is reconfigured from the $12 \mathrm{~km}$ simulation at $T+1$ (i.e. 02:00 UTC on 12 November 2008) and is free-running thereafter, forced at the boundaries by the $12 \mathrm{~km}$ model.

Finally, a $1 \mathrm{~km}$ horizontal grid-length inner domain is used and runs with no convection parametrization. The only other difference from the $4 \mathrm{~km}$ model is a variable coefficient for horizontal diffusion, based on the method of Smagorinsky (1963). Again, this model is re-configured at $T+1$ from the $4 \mathrm{~km}$ domain (i.e. at 03:00 UTC on 12 November 2008) and 
is free-running, forced at the boundaries by the $4 \mathrm{~km}$ model.

We evaluate the model cloud and drizzle by comparison to observations from the $94 \mathrm{GHz}$ (W-band) cloud radar and $6 \mathrm{GHz}$ (C-band) scanning radar, ceilometer and microwave radiometer located on the Ron Brown research vessel, and temperature and humidity profiles from radiosondes launched from the Ron Brown. We also obtain estimates of the variability surrounding the ship from satellite observations of cloud cover from GOES-10 and liquid water path from AMSR-E, SSMI and TMI. In addition, we employ in-situ measurements of temperature, humidity, liquid water content and the cloud/precipitation size distribution from the BAe-146 and C-130 research aircraft. More details of the observational platforms can be found in Wood et al. (2011).

Finally, since we anticipate from previous studies that the representation of drizzle in the simulations is likely to be poor, we also conduct a modified microphysics simulation with the $1 \mathrm{~km}$ model, in which two simple changes are made to the microphysics representation of the MetUM. Firstly, we implement the autoconversion parametrization of Khairoutdinov and Kogan (2000), instead of the MetUM's default Tripoli and Cotton (1980) scheme. Autoconversion represents the collision and coalescence process by which small cloud droplets grow into larger rain droplets. Wood (2005) has demonstrated that the Tripoli and Cotton (1980) parametrization significantly over-estimates the autoconversion rate in stratocumulus clouds, and that the Khairoutdinov and Kogan (2000) parametrization agrees much better with observations. Secondly, we implement the rain drop size distribution (DSD) derived in Abel and Boutle (2012), rather than the MetUM's default Marshall and Palmer (1948) parametrization. Within a single-moment microphysics scheme, such as that of the MetUM, precipitation is represented with a single prognostic variable, the rain mass mixing ratio $\left(q_{\mathrm{r}}\right)$, and the DSD is represented by an exponential distribution. Abel and Boutle (2012) showed that whilst an exponential size distribution does fit observations very well, the assumption of a fixed intercept parameter of the DSD, $N_{0}=8 \times 10^{6} \mathrm{~m}^{-3} \mathrm{~m}^{-1}$ as used in Marshall and Palmer (1948), is very poor for drizzling stratocumulus. Observations show higher concentrations of smaller drizzle drops in stratocumulus than the Marshall and Palmer (1948) DSD predicts, and Abel and Boutle (2012) suggest a variable $N_{0}$, which is a function of $q_{\mathrm{r}}$ and matches observations of the DSD better across a wider range of rain rates.

\section{Case study overview}

Figure 2 shows a timeseries of radar reflectivity and liquid water path over the Ron Brown during the case study period. The liquid water path was retrieved from a microwave radiometer according to Zuidema et al. (2005). Cloud base derived from a ceilometer and cloud top obtained from the radar are shown, as are the inversion heights as measured by the three-hourly radiosondes. For each radiosonde ascent, we define whether the profile is well-mixed or decoupled based on the difference between the lifting-condensation level $\left(z_{\mathrm{LCL}}\right)$ and cloud base $\left(z_{\mathrm{b}}\right)$ as defined in Jones et al. (2011): $\Delta z_{\mathrm{b}}=z_{\mathrm{b}}-z_{\mathrm{LCL}}>150 \mathrm{~m}$ implies decoupling. There is a distinct diurnal evolution of the cloud, precipitation and boundary-layer structure over the two-day period. During the first night (up to $\approx 11: 00$ UTC), the boundary layer is well-mixed, with relatively low liquid water paths (LWPs) around $60 \mathrm{gm}^{-2}$ and very little precipitation below the observed cloud base. Around 12:00 UTC, the cloud starts to thicken and precipitate, with LWP values reaching $200 \mathrm{gm}^{-2}$ and radar reflectivities of $-30 \mathrm{dBZ}$ extending near to the surface (we do not show radar returns below $150 \mathrm{~m}$ due to noise). After this, during the day, the cloud thins and almost disappears around 18:00 UTC, with the drizzle reducing and ultimately stopping. The cloud base also rises during the day and the boundary layer decouples. During the second night (after 00:00 UTC), the cloud thickens and starts to precipitate again. The cloud top inversion rises slightly during the night, which is a sign of increased cloud-top entrainment. This is consistent with a well-mixed boundary layer and increased turbulence driven by radiative cooling at the cloud top. Similar to the first day, after $\approx 12: 00$ UTC the cloud thins and precipitation stops during the second day. The boundary layer also decouples more strongly on the second day, shown by a greater number of radiosonde ascents being classed as decoupled. The strength of the decoupling $\left(\Delta z_{\mathrm{b}}\right)$ is also greater on the second day. Profiles from the research aircraft and satellite LWP retrievals are all in good agreement with the Ron Brown observations, showing that this strong diurnal cycle in LWP, precipitation and boundary-layer structure is typical of this region of the South-East Pacific.

We do not expect the model grid-point closest to the Ron Brown to mirror this evolution exactly, so here and throughout the paper we present model results from a $1^{\circ}$ region surrounding the Ron Brown to give us some estimation of the variability in the model simulations. Figure $2 b$ shows that the $1 \mathrm{~km}$ control simulation does not show such a strong diurnal cycle in LWP, with only a slight increase during the night-time. For the whole of the second night, the observed LWP values lie outside the range of modelled LWP values in the vicinity of the Ron Brown, showing that this underestimation of night-time LWP is a consistent feature of the MetUM simulation. The evolution of LWP in the lower resolution simulations is almost identical to that of the $1 \mathrm{~km}$ control simulation, demonstrating that the evolution of LWP is dominated by model parametrizations, particularly those of the boundary layer, microphysics and radiation, and is not improved by increased horizontal or vertical resolution. Comparisons of cloud fraction with GOES-10 (not shown) show that the cloud fraction is well represented at night, and over-estimated during the day. This combination suggests that the model cloud is too thin throughout the diurnal cycle, i.e. the LWP divided by the cloud fraction is always too 

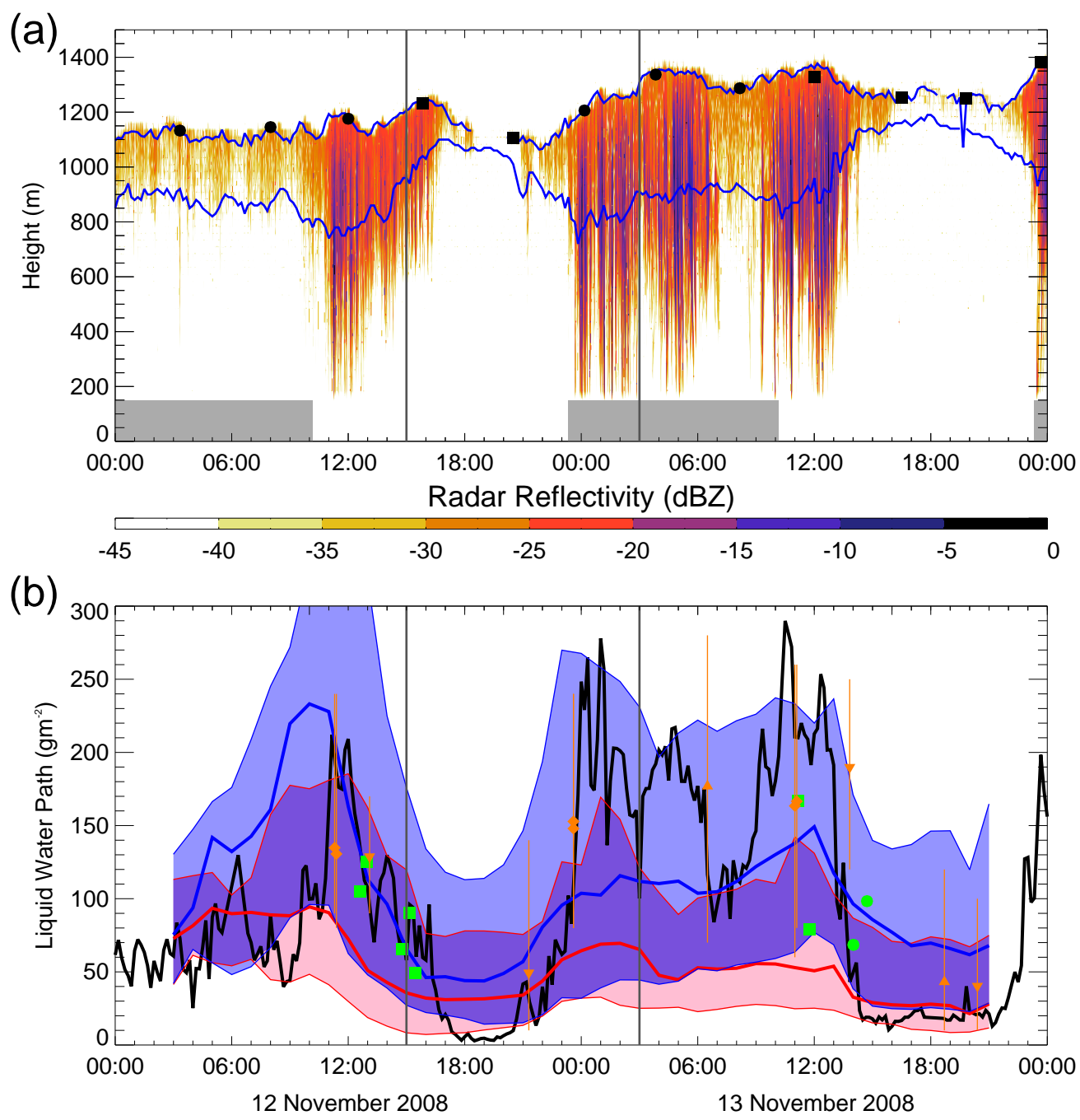

Fig. 2. (a) Radar reflectivity factor (dBZ) from the Ron Brown W-band radar during 12 and 13 November 2008, with cloud base and top (blue) obtained from the ceilometer and radar, respectively. Black symbols represent the radiosonde inversion heights, with circles representing well-mixed profiles and squares decoupled profiles. The grey shading marks night-time, as defined by an absence of downwelling short-wave radiation measured at the Ron Brown. (b) Liquid water path from the Ron Brown microwave radiometer (black), from the BAe-146 (green squares), C-130 (green circles), AMSR-E (orange upward triangles), SSMI (orange diamonds) and TMI (orange downward triangles). The aircraft profiles are within $2^{\circ}$ of the ship and the satellite observations are a mean over a $2^{\circ}$ region surrounding the Ron Brown, with the bars showing the range of values. Over plotted are the median and 5th/95th percentiles from a $1^{\circ}$ region surrounding the Ron Brown, for the $1 \mathrm{~km}$ control (red) and modified microphysics (blue) simulations. The grey vertical lines show the times of the plots in Figs. 3, 4, 5, 6 and 8.

low. This is generally consistent with the results presented in Wyant et al. (2010).

The simulation with modified microphysics parametrizations has higher values of night-time LWP, in better agreement with the observations. The cloud amount (not shown) is also better at night, although both the LWP and cloud cover during the day-time are now too high. This worsening during the day is mainly due to there being too much cloud cover, the in-cloud LWP (i.e. LWP divided by cloud fraction) is now much better throughout the diurnal cycle. Whereas the control simulation continually under-estimated the in-cloud LWP, the modified microphysics simulation appears to have corrected this, but over-forecasts the frequency of cloud during the day-time. As discussed below, part of the reason for this is a poor representation of coastal clearing of the cloud during the day, and as shown in Fig. 2b, the satellite LWP measurements do show some high values in the vicinity of the ship. Reasons for the improvement of this simulation will be investigated further in Sects. 4 and 5 . 

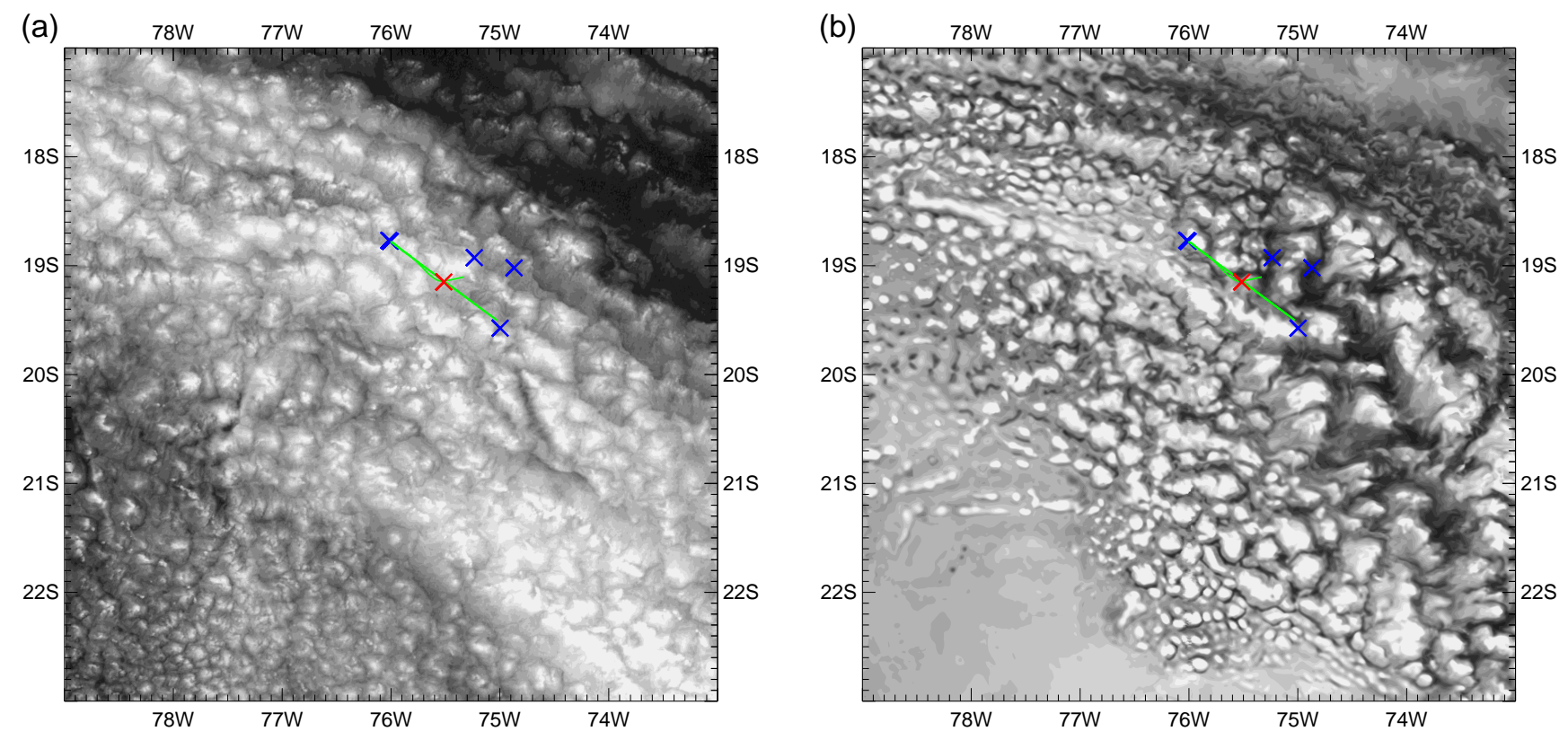

Fig. 3. (a) Visible satellite image from GOES-10 at 15:00 UTC on 12 November 2008. (b) MetUM simulated short-wave upwelling radiation at top-of-atmosphere, from the $1 \mathrm{~km}$ control simulation at the same time. The red cross shows the position of the Ron Brown at this time, with profile ascent/descent locations (blue) and straight and level runs (green) of the BAe-146 near this time.

We select two times, one during the day (15:00 UTC on the 12th) and one during the night (03:00 UTC on the 13th) to investigate the diurnal evolution in more detail. Figure 2 shows that 03:00 UTC is typical of much of the night-time, whilst 15:00 UTC gives a day-time comparison when there is still some cloud present, and is co-incident with an intercomparison flight of the BAe-146 giving us many additional measurements.

Figure 3 shows a comparison of the visible satellite image at 15:00 UTC on 12 November 2008 from GOES-10 with the short-wave upwelling radiation at top-of-atmosphere simulated in the $1 \mathrm{~km}$ control model. The satellite image shows three distinct regions within the cloud field. In the north-east corner of the domain, there is a relatively cloud free region, with a boundary extending diagonally from $20^{\circ} \mathrm{S}$ on the east boundary to $77^{\circ} \mathrm{W}$ on the north boundary. This cloud free region is a diurnal feature, where the cloud clears near to the coast during the day and re-forms at night, and is discussed in more detail in Abel et al. (2010). It is believed to be a dynamically forced phenomenon, and the model does appear to be partly capturing it. There is a distinct boundary within the MetUM simulated cloud field, in approximately the correct location. However, the coastal region has too much cloud present. The cloud free periods over the Ron Brown around 18:00 UTC, shown in Fig. 2, are when this coastal clearing is at its maximum extent and reaches the location of the ship. The fact that the model is unable to clear the cloud from this region explains why the sim- ulated cloud amount and LWP is too high during this period of the day. The failure of the model to clear the cloud is related to the diagnostic cloud parametrization of Smith (1990), which calculates the cloud fraction and condensate based on a triangular shaped sub-grid moisture distribution, with the width given by a prescribed value of relative humidity $\left(\mathrm{RH}_{\text {crit }}\right)$. Radiosonde ascents from the coastal station at Iquique $\left(70.13^{\circ} \mathrm{W}, 20.27^{\circ} \mathrm{S}\right)$, and profiles from the research aircraft, show that the relative humidity is still quite high in this cloud free region, such that for the prescribed $\mathrm{RH}_{\text {crit }}$ value $(\approx 0.8)$, the model would always produce some cloud even if it were simulating the temperature and humidity profiles perfectly, due to part of the distribution being saturated. More research is clearly required to establish how to implement a cloud parametrization at this resolution, if one is even required at all.

The second region, located in the south-west corner of the domain and bounded by a diagonal line extending from $74^{\circ} \mathrm{W}$ on the southern boundary to $20^{\circ} \mathrm{S}$ on the western boundary, contains closed-cellular convection. The scale of the cells appears quite small. The model also appears to capture the boundary to this region relatively well, again suggesting that the boundary is a dynamically forced phenomenon. The model does not appear able to resolve the small scale of the convection, instead producing a relatively uniform cloud field in which the mixing is still parametrized by the boundary-layer scheme. This is likely to be due to the horizontal resolution used - at $1 \mathrm{~km}$ the model is only 
DAY

(a) 15 UTC, 12 November 2008
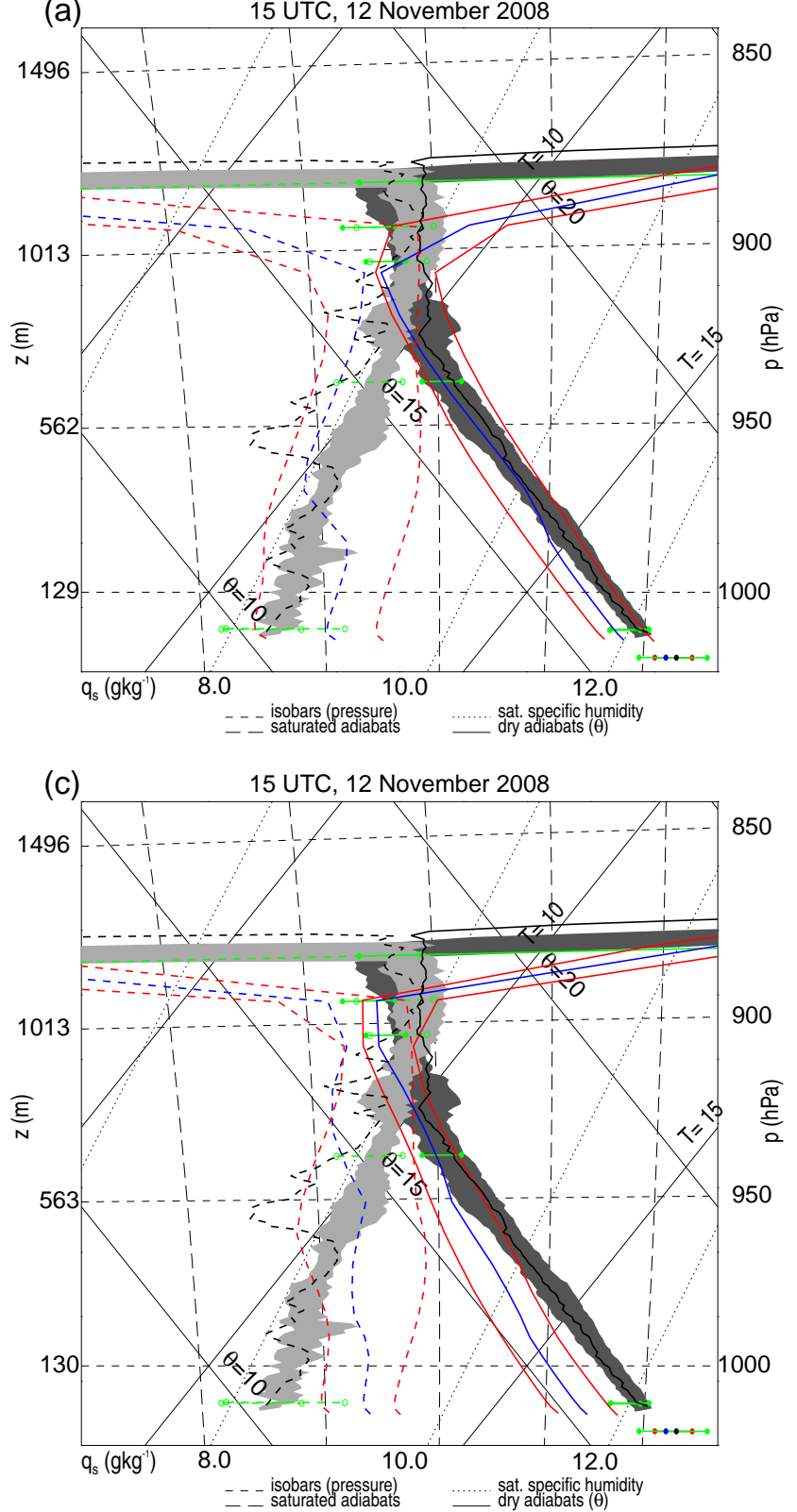

NIGHT

(b)

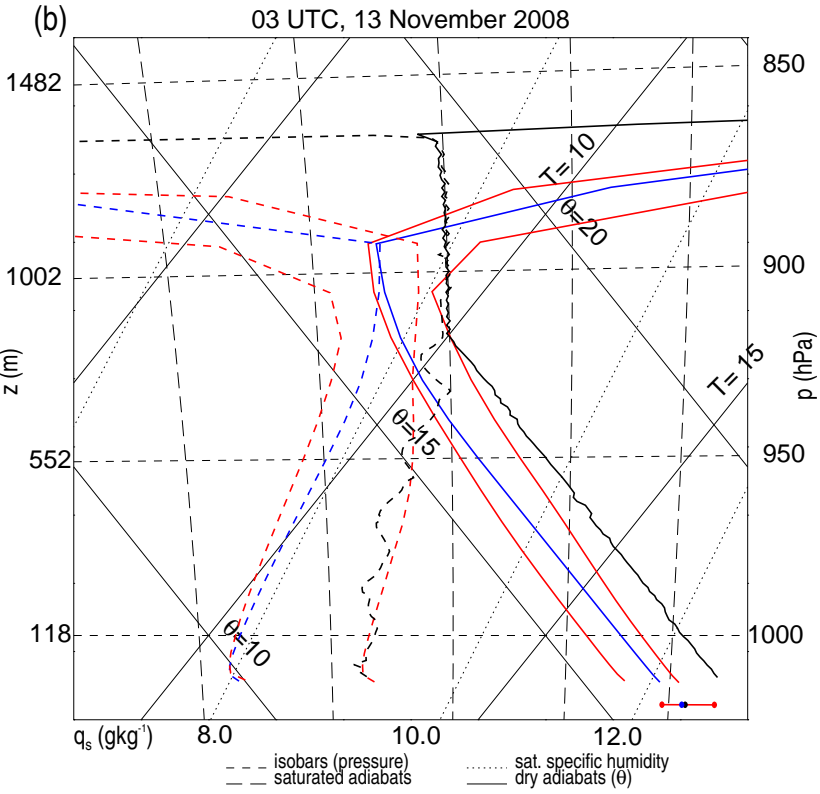

(d)

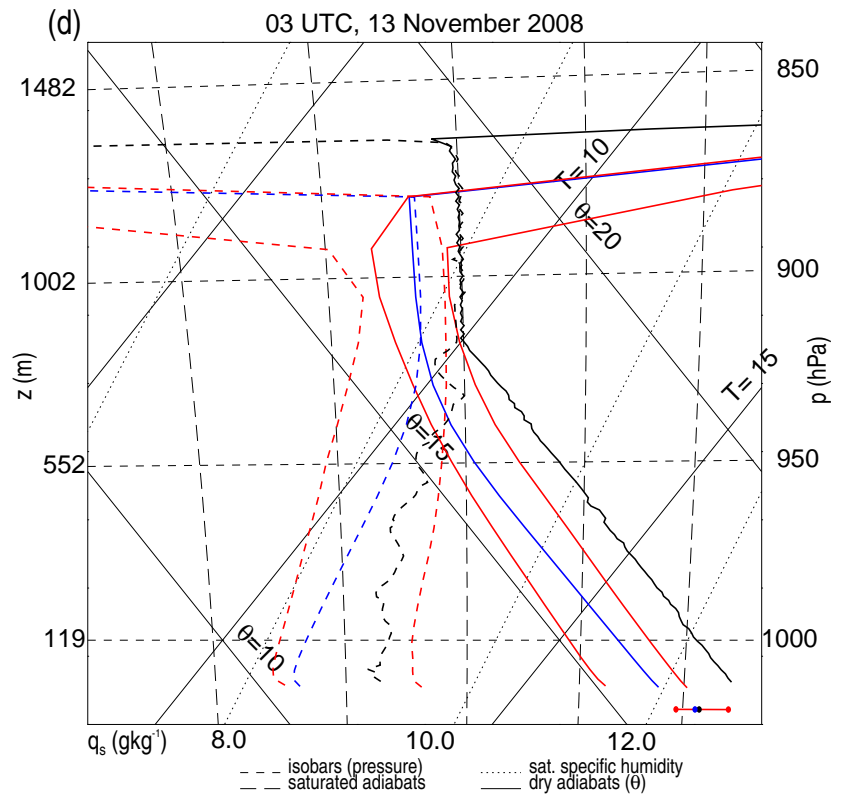

Fig. 4. Radiosonde profiles from the Ron Brown (black) with variability from 5 BAe-146 profiles (grey shading) and 6 straight and level runs (green). Over-plotted is the model profile from the grid-point nearest to the Ron Brown (blue) and the 5th/95th percentiles from a $1^{\circ}$ box surrounding the Ron Brown (red), for the $1 \mathrm{~km}$ control (a and $\mathbf{b}$ ) and modified microphysics (c and d) simulations. The values in the bottom right corner represent the sea-surface temperature.

truly capable of resolving the larger convective cells. The prevailing wind is from the south, and so there is also likely to be some spin-up along the southernmost boundary of the domain. The final region, in the centre of the domain and surrounding the Ron Brown, contains a much brighter region of cloud, again with closed cellular convection but with much larger convective cells. This region is reproduced very well by the $1 \mathrm{~km}$ model, with the closed cellular structure clearly visible and the scale of the convective cells appearing to be approximately the same, although the dark edges of the cells appear larger, suggesting that the downdraft regions are too wide. It is also clear from this image that the structure of the cloud field is the same across a $1^{\circ}$ region surrounding the Ron Brown, justifying our method of interpreting the model simulations based on this region. 
It is only in the $1 \mathrm{~km}$ simulation that such detail is visible in the cloud field. At lower resolutions the model does not explicitly resolve the convective cells, instead the convection is parametrized and the cloud field appears uniform across the domain. The coastal clearing is completely absent from the global and $12 \mathrm{~km}$ models, with just a faint hint of its appearance apparent at $4 \mathrm{~km}$. It therefore appears that horizontal resolutions of order $1 \mathrm{~km}$ are required to represent the mesoscale variability of cloud fields, but also that further work is required to make model parametrizations suitable for this scale of NWP.

\section{Boundary-layer structure}

Figure 4 allows us to suggest some reasons for the poor representation of the LWP diurnal cycle in the control simulation, and its improvement in the modified microphysics simulation. The figure shows tephigrams in the vicinity of the Ron Brown during the day-time and night-time. These profiles are typical of other times and locations as measured by the BAe-146 and C-130, with the shading at 15:00 UTC showing that the BAe-146 profiles are in good agreement with the radiosonde. The control model is capable of simulating a boundary layer of approximately the correct depth. The inversion is slightly too low, consistent with the low bias in cloud top height shown in Abel et al. (2010), which results in a sub-cloud layer that is typically colder and moister than the observed profiles. During the day-time, the Ron Brown radiosonde in Fig. 4a shows a weakly decoupled boundary layer $\left(\Delta z_{\mathrm{b}}=220 \mathrm{~m}\right)$, with a slight change in the temperature and moisture profiles around $500 \mathrm{~m}$. The BAe- 146 profiles show that the boundary layer is transitioning during the observation period, consistent with diurnal decoupling as the insolation increases during the day. Based on the total water mixing ratio $\left(q_{\mathrm{T}}\right)$ and liquid water potential temperature $\left(\theta_{1}\right)$ decoupling metrics defined in Jones et al. (2011), the first two aircraft profiles are well-mixed and the final three are decoupled, although all profiles are very close to the thresholds. Figure 2 a shows that the cloud base rises by $\approx 200 \mathrm{~m}$ during the period of the BAe-146 profiles, with the lifting condensation level remaining around $800 \mathrm{~m}$, which again results in the $\Delta z_{\mathrm{b}}$ metric diagnosing well-mixed boundary layers initially and decoupled boundary layers for later profiles. The model profiles are generally able to capture this decoupled structure, although the extent of the decoupling appears much stronger, as shown by the larger change in temperature and dewpoint than was observed, lower in the atmosphere, at around $250 \mathrm{~m}$ in Fig. 4a. The Lock et al. (2000) boundary-layer scheme diagnoses a decoupled stratocumulus layer for the nearest grid-point to the Ron Brown, and $75 \%$ of those within the $1^{\circ}$ radius. The model is typically too moist in the sub-cloud layer, although the observations do lie within the range of model variability. Modelling this boundary-layer structure is something that does improve with horizontal and vertical resolution. In the global and $12 \mathrm{~km}$ models, the inversion is lower, a likely symptom of the coarser vertical grid, forcing the sub-cloud layer to be colder and moister still. This results in most of the domain $(80 \%$ at $12 \mathrm{~km}$ and $100 \%$ at global resolution) diagnosing cumulus convection beneath the stratocumulus, something which was not observed on this day.

During the night-time, the profile in Fig. $4 \mathrm{~b}$ shows a single mixed-layer, with temperature and moisture profiles wellmixed from the surface up to the cloud layer, which is just a thick layer of capping stratocumulus. This explains the reason for the observed strong diurnal cycle in LWP. During the day-time, the cloud layer is typically decoupled from the surface, and so the moisture supply to the cloud layer is cutoff, and the cloud thins due to short-wave heating. During the night, the cloud-layer re-couples to the surface, allowing moisture to be mixed up into the cloud layer, forming a thick layer of stratocumulus with high LWP. The model, however, is unable to fully represent this behaviour. The model profile looks more well-mixed than it does during the day, explaining the slight increase in LWP, although the boundarylayer scheme is still diagnosing this as a decoupled boundary layer. This prevents the model from mixing the surface moisture supply up into the cloud layer, explaining the low LWP. This profile is typical of the surrounding region, with $70 \%$ of the grid-points still being diagnosed as decoupled and only $5 \%$ are diagnosed as well-mixed (the rest involving some cumulus convection). Decoupled boundary layers are persistent throughout the entire night in this simulation, and there is very little signal that the decoupling is correlated with the solar radiation. The radiosonde profile shows that the cloud top inversion rises slightly during the night-time, and this is likely to be due to increased entrainment from the cloud-top, due to stronger night-time radiative cooling from the cloud top driving negatively buoyant plumes, which entrain some warmer air from the free troposphere with them. The model does not show this increase in inversion height during the night, and this is due to the weak diurnal cycle in boundary-layer type keeping the entrainment rate approximately constant throughout the period. It is also noticeable that the observed temperature profile is warmer than the seasurface temperature at night, which would result in a negative surface sensible heat flux, which was indeed observed by the Ron Brown. The surface latent heat flux remains large and positive however, ensuring that the total surface buoyancy flux remains positive throughout the diurnal cycle. Because the model profile is too cold, it maintains a positive surface heat flux throughout the night.

Figure $4 \mathrm{~d}$ shows that the modified microphysics simulation has a more well-mixed boundary layer during the night, which explains the increased LWP seen in this simulation. This coupled boundary layer allows the model to mix more moisture from the sub-cloud layer into the cloud layer, thickening the cloud and increasing the LWP. The increased LWP also leads to greater cloud top radiative cooling, driving stronger negatively buoyant plumes, further enhancing the 
coupling between the cloud layer and surface. This also increases the cloud top entrainment, raising the inversion slightly, although it is still not as high as was observed. The model is now diagnosing roughly a $50 / 50$ split between decoupled and coupled boundary layers at this time, with the presence of coupled grid points reaching $80 \%$ at some points during the night. The simulation has improved the boundarylayer structure throughout the diurnal cycle, with $70 \%$ of the region being diagnosed as decoupled during the day-time and a clear transition between coupled and well-mixed boundary layers around dawn and dusk. Figure $4 \mathrm{c}$ also shows that the extent of the decoupling looks weaker during the day than it did in the control simulation, but the sub-cloud layer now appears to be colder and moister, and is now outside the region of observational variability. In Sect. 5 we will demonstrate that the poor diurnal cycle in the control simulation is due to excessive drizzle production, and that an improved representation of drizzle in the modified microphysics experiment is responsible for the improvements to the boundary-layer diurnal cycle.

Figure 5 compares the liquid water content observed from the BAe-146 profiles around the Ron Brown at 15:00 UTC with the model variability. The slight under-estimation in the cloud-top height is noticeable, but also there is a much larger under-estimation in the cloud base height. There is also a general under-estimation in the peak liquid water content, with the observed values lying outside the model variability for the $1 \mathrm{~km}$ control simulation and only just within it for the modified microphysics simulation. This shows that the improvement in LWP for the modified microphysics simulation, shown in Fig. 2b, is not entirely for the correct reasons. The observed profile shows a thin layer of cloud, with a peak liquid water content around $0.6 \mathrm{~g} \mathrm{~kg}^{-1}$, whilst the model simulations both show a thicker layer of cloud with lower peak water contents. When integrated to give the LWP, the modified microphysics simulation has the correct total. The low cloud base values observed in the model are again likely to be related to the diagnostic cloud scheme used in the MetUM. The relative humidity is high enough in this region such that for the given value of $\mathrm{RH}_{\text {crit }}$, part of the grid-box is assumed to be saturated. The cloud fractions in the region below $\approx 700 \mathrm{~m}$ are very low $(\approx 0.1)$. The lower cloud base for the modified microphysics simulations is consistent with the profiles shown in Fig. 4c, which shows that this simulation is slightly colder and moister in this region, resulting in a higher value of relative humidity and more of the grid-box being saturated. Again, the applicability of such a diagnostic cloud parametrization at $1 \mathrm{~km}$ requires further investigation.

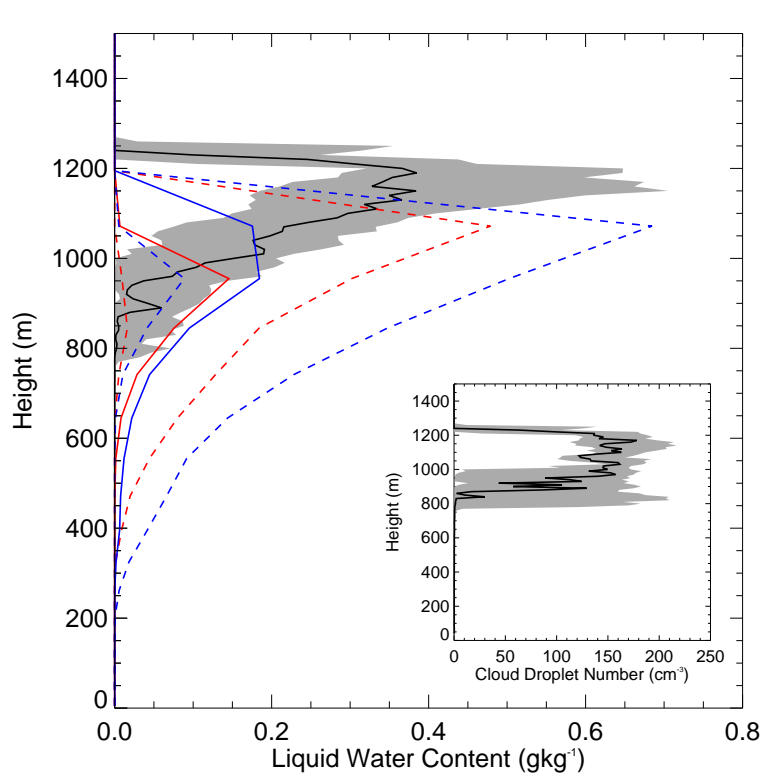

Fig. 5. Observed liquid water content median (black) and range (grey shading) from the profile ascent/descents of the BAe-146 near the Ron Brown around 15:00 UTC on 12 November 2008. Overplotted are the median and 5th/95th percentiles from a $1^{\circ}$ region surrounding the Ron Brown from the $1 \mathrm{~km}$ control (red) and modified microphysics (blue) simulations. The inset panel shows the observed cloud droplet number concentrations from these flights.

\section{Drizzle representation}

We have explicitly chosen not to investigate the spatial or temporal variability of cloud droplet number concentration in this study. The MetUM uses a fixed value of $100 \mathrm{~cm}^{-3}$ for the cloud droplet number concentration over the sea, whilst observations from the research aircraft show that near the Ron Brown it is typically higher $\left(\approx 150 \mathrm{~cm}^{-3}\right.$, shown in Figure 5), but the flights further from the coast during the 13th encountered much lower concentrations $\left(\approx 50 \mathrm{~cm}^{-3}\right.$, not shown). Values for the entire VOCALS period are discussed in Allen et al. (2011), who show that the high values near the coast are due to pollution being advected away from the continent. If these variations were to be modelled in the MetUM, the likely effect would be to increase the peak liquid water content in the vicinity of the Ron Brown, because the modelled autoconversion of cloud liquid into rain is inversely proportional to the cloud droplet number concentration. There is also likely to be a bigger effect for the modified microphysics simulation, since the Khairoutdinov and Kogan (2000) autoconversion scheme has a much stronger dependence on the cloud droplet number than the Tripoli and Cotton (1980) parametrization. 
(a)

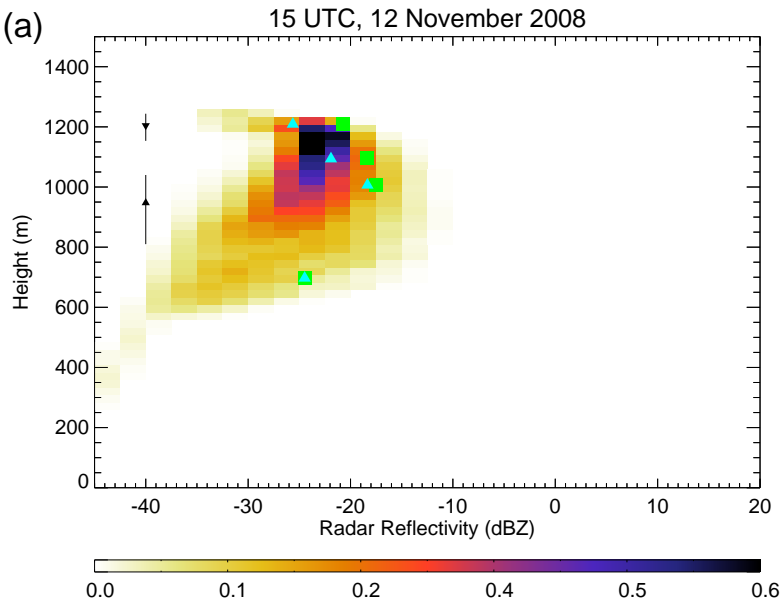

(c)

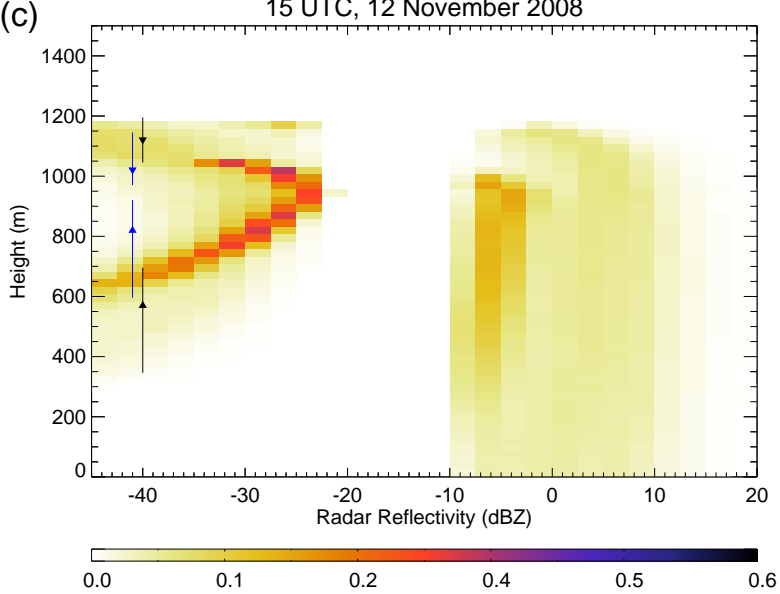

(e)

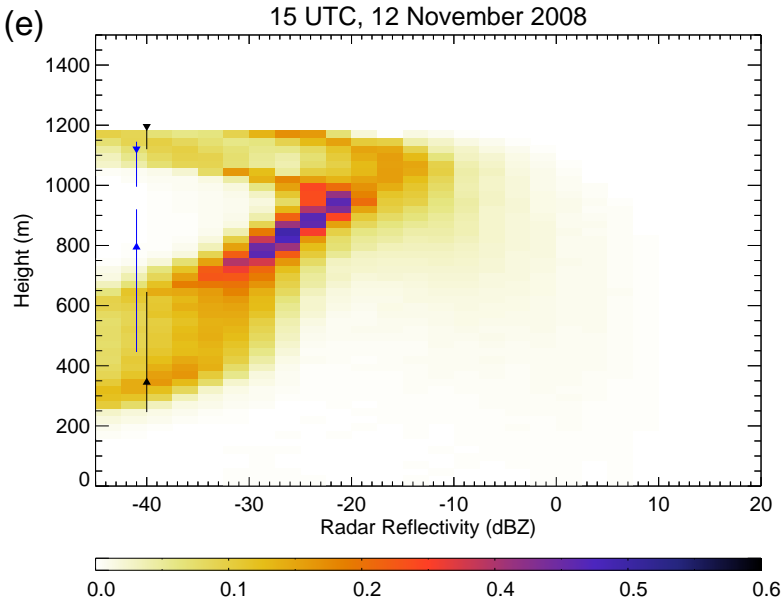

(b) 03 UTC, 13 November 2008

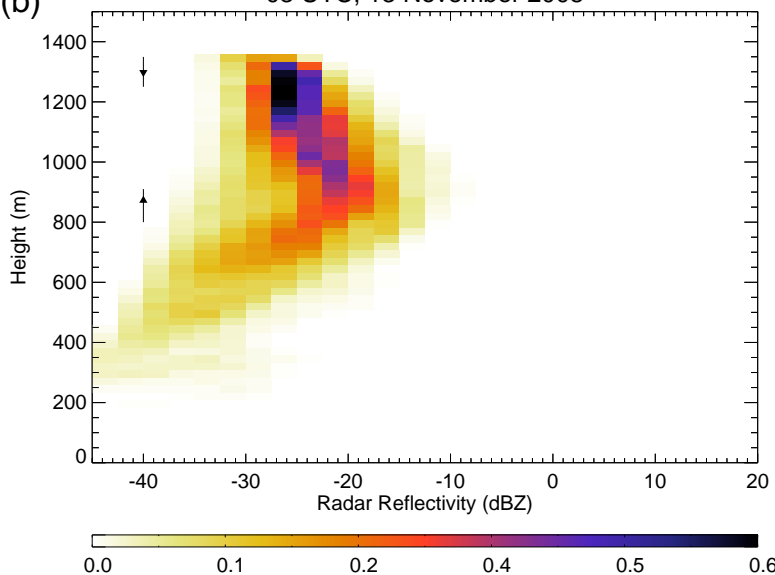

(d)
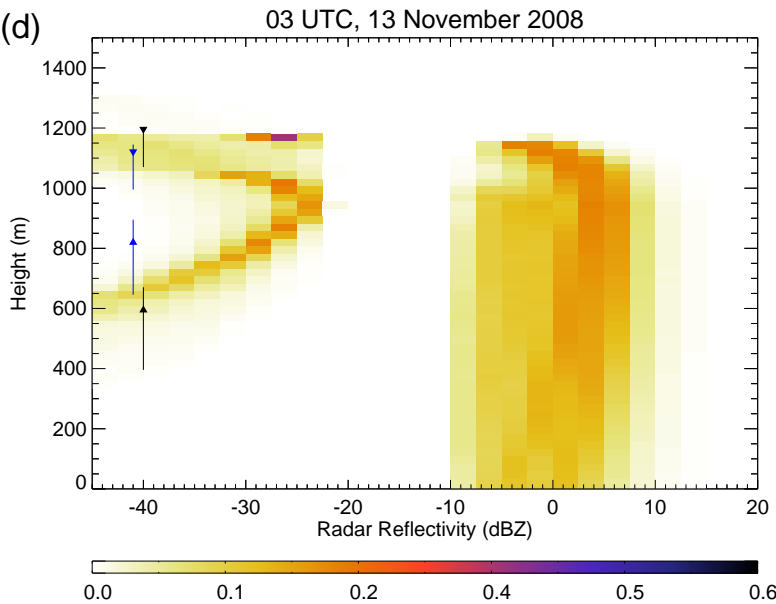

(f)

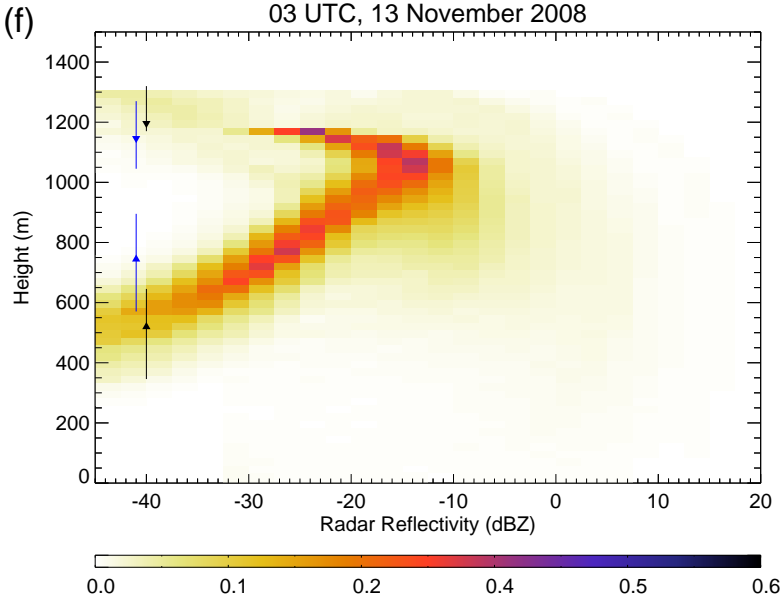

Fig. 6. Normalised histograms showing W-band radar reflectivity versus height from the Ron Brown for 30 min either side of the time shown (a and b). MetUM histograms taken from a $1^{\circ}$ box surrounding the Ron Brown at the time shown, for the $1 \mathrm{~km}$ control (c and d) and modified microphysics (e and f) simulations. The green boxes represent estimated radar reflectivity from the BAe-146 in-situ measurements of the cloud and drizzle DSD, and the blue triangles the same estimate using only particles $>50 \mu \mathrm{m}$. The black triangles and whiskers show the median and maximum/minimum cloud top height and base. For the model (c-f), the black shows the range calculated using cloud fraction $>0$ and blue shows the range calculated using cloud fraction $>0.5$. 
Figure $6 \mathrm{a}, \mathrm{b}$ shows histograms of radar reflectivity versus height from the $94 \mathrm{GHz}$ vertically pointing cloud radar located on the Ron Brown, for a $1 \mathrm{~h}$ period either side of 15:00 UTC and 03:00 UTC. As shown, there is a continuous distribution of radar reflectivity, with cloud and drizzle falling below cloud base both visible. The average radar reflectivity calculated from integrating the particle sizedistributions measured from level runs of the BAe-146 aircraft over the Ron Brown are also shown in Fig. 6a. Two estimates are included, which represent the reflectivity calculated from the measured size distribution of cloud and drizzle droplets, and the reflectivity calculated from the drizzle sized drops only $(D>50 \mu \mathrm{m})$. The difference between the two estimates shows the contribution of cloud droplets to the total reflectivity. Collision and coalescence processes lead to an increase in cloud drop size near cloud top and there is a corresponding increase in the contribution of cloud drop sized particles to the reflectivity. Drizzle sized drops are generated near cloud top and fall back through the cloud layer accreting cloud water. This leads to an increase in the drizzle drop size and the measured reflectivity towards cloud base. The aircraft observations below cloud base at $700 \mathrm{~m}$ show that the reflectivity is entirely due to drizzle sized droplets and that the reflectivity is lower than at cloud base due to evaporation of drizzle in the sub-cloud layer. The radar histograms show a similar pattern, with the reflectivity increasing in the cloud layer as the drizzle increases. The maximum is observed around cloud base, with reflectivity values reducing below the cloud as the drizzle evaporates. No drizzle reaches the surface at 15:00 UTC, with only a small amount at 03:00 UTC, consistent with Fig. 2a (again, we do not show radar returns below $150 \mathrm{~m}$ ).

Figure $6 \mathrm{c}$,d shows that the control simulation has a distinctly bi-modal structure in the reflectivity profile. There is a cloud mode, with reflectivities below $-20 \mathrm{dBZ}$, and a drizzle mode with reflectivities above $-10 \mathrm{dBZ}$. Calculating the reflectivities using model cloud and model rain separately confirms that the high values are due to the rain only and the low values are due to the cloud only. It is also noticeable that there is very little reduction in reflectivity below the cloud base, with similar reflectivity values simulated at the cloud base and at the surface, indicating high cloud-base and surface drizzle rates. This is similar to the results shown by Bodas-Salcedo et al. (2008) and Abel and Boutle (2012). Also shown is the variability in cloud base and top. We provide two estimates of each of these, following the discussion around Fig. 5. Defining the cloud as the region where cloud fractions are $>0.5$ seems to provide a better estimate of the location of the bulk of the cloud, removing the very low cloud fractions seen below $700 \mathrm{~m}$.

The modified microphysics simulation, shown in Fig. 6e,f, no longer shows the bi-modal structure of reflectivity profiles, matching the observations much better. There is now a continuous transition from cloud to drizzle, and also some reduction in reflectivity below the cloud base, indicating a much lower surface drizzle rate. This enhanced evaporation is consistent with the results of Abel and Boutle (2012), and helps to explain why the sub-cloud layer is cooler and moister in this simulation, as shown in Fig. 4. As the drizzle evaporates below cloud base, it will cool and moisten the sub-cloud layer. This then has the further effect of increasing the relative humidity, which results in the cloud scheme producing some small cloud fractions. Here, the two methods of defining cloud base produce very different results at 15:00 UTC. Everywhere drizzle is present there is also some cloud present, but defining the cloud layer as the region where cloud fractions are $>0.5$ gives a cloud layer similar in depth to that observed, and some drizzle evaporating below the cloud base.

Figure 7 shows normalised histograms of the cloud-base drizzle rate against the cloud LWP. Here, the definition of cloud base becomes important, and we chose to define it as the point at which cloud fractions fall below 0.5 . This is because the cloud base drizzle rate is used by Comstock et al. (2004) to represent the peak rainfall rate, below which evaporation is the dominant process rate and the rainfall rate reduces. For cloud fractions lower than 0.5, the majority of the grid-box is cloud-free, and therefore evaporation is the dominant process rate. As shown in Fig. 6, the peak in radar reflectivity is observed at cloud base in reality but actually slightly above it in the model. If cloud base were taken to be the point at which cloud fractions reached zero, in the modified microphysics simulation, all the rain has evaporated by this point.

Figure 7a shows a good relationship between the two quantities, which matches well the relationship discussed in Comstock et al. (2004), which is based on observations taken in this region of the South-East Pacific. However, the data fit is not at the expected value of $100 \mathrm{~cm}^{-3}$, the fixed value of $N_{d}$ used in the MetUM, but at a much lower value nearer $50 \mathrm{~cm}^{-3}$, similar to the results presented in Abel et al. (2010). This suggests that the model is too efficient at producing drizzle, i.e. for a given LWP and cloud droplet number, the model produces too much cloud-base drizzle. The use of the Khairoutdinov and Kogan (2000) autoconversion parametrization (Fig. 7b) in the modified microphysics simulation slows down the production of drizzle in the cloud layer, resulting in a much better fit to the $100 \mathrm{~cm}^{-3}$ cloud droplet number curve.

Figure 8 shows a comparison of radar reflectivity from the $6 \mathrm{GHz}$ scanning radar located on the Ron Brown with the same quantity simulated in the MetUM. The plots show the highest reflectivity observed in each atmospheric column. The model plots are adjusted to only show reflectivities that would be visible to the radar. Much of the white space in the model plots actually contains values of reflectivity between -10 and $-20 \mathrm{dBZ}$, which we expect is present in reality, but cannot be seen by the radar. Similar to Figs. $2 \mathrm{a}$ and $6 \mathrm{a}, \mathrm{b}$, there are very few reflectivity returns at greater than $0 \mathrm{dBZ}$ shown in Fig. 8a,d, demonstrating that the character of the 
(a)

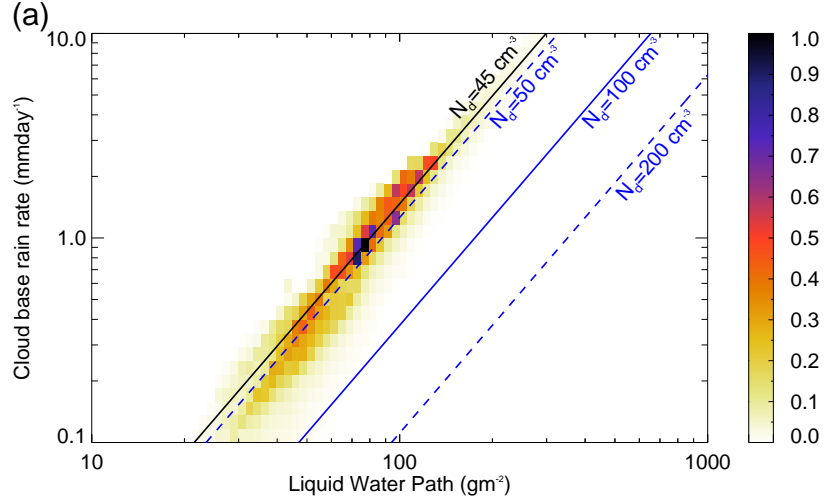

(b)

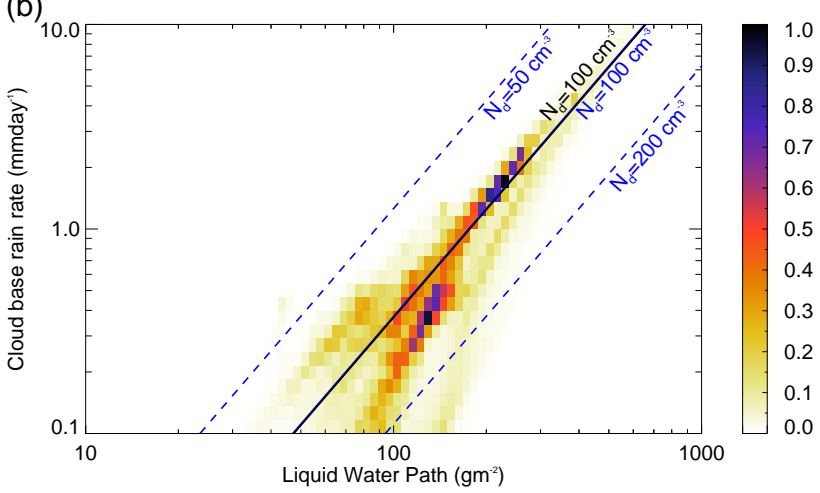

Fig. 7. Normalised histograms of liquid water path versus cloud base rain rate over the two-day period from a $1^{\circ}$ region surrounding the Ron Brown, for the $1 \mathrm{~km}$ control (a) and modified microphysics (b) simulations. The relationships derived by Comstock et al. (2004) for several values of cloud droplet number are shown in blue, with a fit to the data shown in black.

cloud and drizzle surrounding the ship is much the same as was observed over the ship by the cloud radar. During the day, there is very little precipitation at all, whilst during the night, there are some cells of drizzle, but on the whole the radar is observing very light rain. By contrast, Fig. 8b,e shows that the $1 \mathrm{~km}$ control simulation has high $(>5 \mathrm{dBZ}$ ) values of reflectivity throughout the domain. Almost all the cloud is drizzling, and some of the cells are quite intense, with reflectivities in excess of $20 \mathrm{dBZ}$. At night, $54 \%$ of the region is showing detectable reflectivity returns, compared to only $13 \%$ of the observations, and the average reflectivity return is too high by $\approx 10 \mathrm{dBZ}$. Comparisons of similar radar scans throughout the two-day case study shows that the model consistently has reflectivity values too high throughout too much of the domain.

In the modified microphysics simulation, Fig. 8c,f shows that the extensive drizzle across much of the domain is significantly reduced. There are only a few small cells of relatively light drizzle remaining. The spatial coverage of detectable reflectivities is just $11 \%$ during the night, much closer to the observed value. The average radar return is still too high by $\approx 5 \mathrm{dBZ}$, although this is heavily skewed by the single cell visible $30 \mathrm{~km}$ east of the Ron Brown, which is very intense. If this is removed from the statistics, the average reflectivity now matches the observations very well. There are however still too few cells, which are typically too large in size. The average cell size during the night is $13.9 \mathrm{~km}^{2}$ in the observations (ignoring cells which are smaller in size than the model grid), compared to $35 \mathrm{~km}^{2}$ in the model. This implies that there are just under half the number of cells modelled as were observed. It is likely that the size and intensity of these cells is now constrained by the model resolution and lack of a convection parametrization, than any microphysical aspects. The convective cells must reach a certain size before the model grid can explicitly represent the convection (around 5 grid-lengths), meaning that the model can only simulate convective cells several kilometers in diameter. The radar shows that cells much smaller than this are observed in reality, and only if the model grid-length were nearer to $100 \mathrm{~m}$ could these be fully represented.

The representation of the drizzle in the control simulation, and its improvement in the modified microphysics simulation, allows us to suggest some reasons for the changes seen in LWP and boundary-layer structure. In the control simulation, the microphysics parametrization is too efficient at converting cloud liquid water into drizzle, making the cloud base drizzle rate too high. Although the sub-cloud evaporation rate is under-estimated in the control simulation, the excessive cloud base drizzle means there is still a significant amount of evaporation happening below cloud base, which can be seen in Fig. 6c,d by a reduction in reflectivity returns towards the ground. The reduction in reflectivity from 10 to $0 \mathrm{dBZ}$ shown in Fig. 6d actually represents a greater mass of rain being evaporated than the reduction from -10 to $-50 \mathrm{dBZ}$ shown in Fig. $6 \mathrm{f}$, and it is the total mass of rain evaporated that controls how the sub-cloud layer is modified. This evaporation acts to cool and moisten the sub-cloud layer, especially at night when the drizzle is heaviest. Due to the sub-cloud layer being too cold and too moist, the boundary-layer scheme has difficulty overcoming this buoyancy gradient, making it persistently diagnose a decoupled cloud layer. This prevents the cloud layer from recoupling to the surface during the night-time, creating the poor simulation of the cloud LWP. In the modified microphysics simulation, by reducing the autoconversion rate, we have significantly reduced the cloud-base drizzle rate. This means that even when we implement a more realistic DSD which increases sub-cloud evaporation rates, the reduction in cloud base drizzle rate more than compensates for this increase, allowing the model to re-couple the cloud layer to the surface during the night. This allows moisture to be mixed up into the cloud layer, increasing the LWP which in turn 

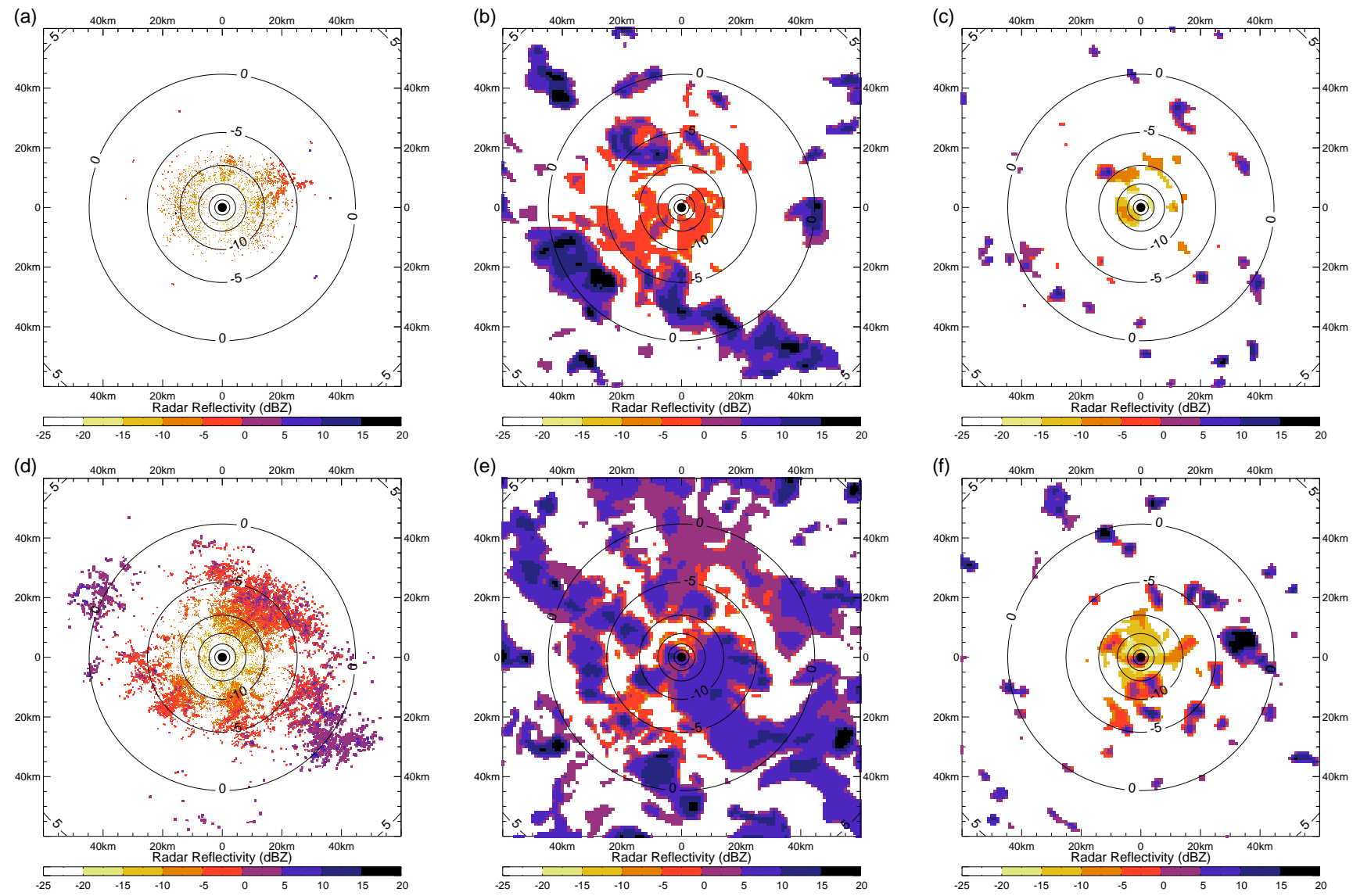

Fig. 8. Radar reflectivity from the C-band radar on the Ron Brown (a and d) with MetUM results from the $1 \mathrm{~km}$ control (b and e) and modified microphysics (c and f) simulations. The top row (a-c) shows 15:00 UTC on 12 November 2008 and the bottom row (d-f) 03:00 UTC on 13 November 2008. Each plot shows the maximum reflectivity in the column, and the circles show the minimum detectable reflectivity of the radar, for which the model plots are adjusted.

results in more cloud top generated turbulence due to radiative cooling, enhancing the coupling. Overall, these microphysical feedbacks significantly improve the diurnal cycle of boundary-layer structure, whilst also improving the surface drizzle rates.

\section{Conclusions}

In this paper, we have discussed the simulation of stratocumulus cloud and drizzle by the MetUM for a case-study during the VOCALS field campaign. A nested suite of simulations at increasing horizontal and vertical resolution showed only small improvements in the cloud and drizzle representation, demonstrating that the representation of these processes is still strongly dependent on the parametrization schemes, and continued investment in improving these parametrizations is crucial for the improvement of NWP and climate models. For example, this paper has raised questions about the implementation and performance of a diagnostic cloud parametrization at high resolution. Clearly further work is required to design and implement a cloud parametrization appropriate for these resolutions.

The MetUM was capable of producing a credible simulation of the chosen case-study, which in itself is not a trivial task. Andrejczuk et al. (2011) conduct high-resolution simulations of the same case study in the Weather Research and Forecasting (WRF) model, and show a very poor agreement of their simulations with observations, although this is more likely to be due to the boundary-layer parametrization than microphysical aspects. Comparison to observations showed that the MetUM simulated a boundary layer of approximately the correct depth, with a reasonable temperature and humidity structure. However, the model was too efficient at converting cloud liquid water into drizzle, resulting in cloud water contents that were typically too low, and drizzle rates in the sub-cloud layer that were too high. An interesting feedback process was established, whereby the poor representation of the cloud microphysics was modifying the entire boundary-layer structure. The excessive drizzle production 
in the cloud layer resulted in too much sub-cloud evaporation of rain. This acted to moisten and cool the sub-cloud layer, stabilising the boundary layer profiles and forcing the boundary layer to become persistently decoupled in structure. This simulated structure was in stark contrast to the observed boundary-layer structure, which during the night-time showed a single mixed layer extending from the surface to the cloud top, with a weakly decoupled structure during the day. This diurnal cycle in boundary-layer type was responsible for the large diurnal range of cloud LWP. Feedbacks like this show why stratocumulus represents such a challenge for GCMs, as many different parametrization schemes are required to work together to produce a realistic simulation.

Two simple improvements to the microphysics parametrization, a modified autoconversion scheme, which improves the transition from cloud water into rain water, and a new representation of the rain water drop size distribution, which matches observations much better, were both implemented. It was shown that these modifications led to improvements in the simulated cloud and precipitation, but also modified the boundary-layer structure via the feedback process described above. It is unsurprising that the two modifications led to model improvements, since they were both, in part, motivated by stratocumulus simulation. Designing parametrizations to improve certain aspects of a simulation without degrading others is a challenging task, and Abel and Boutle (2012) demonstrate how consideration of many different weather regimes is required to develop a parametrization (in their case, the new rain drop size distribution) that works on a global scale. Further work is needed to develop an autoconversion parametrization that works accurately on a global scale. However, the importance of stratocumulus clouds in the climate system means that it is important to understand how the changes to the microphysics parametrizations implemented in this paper may effect climate simulations, both via the direct mechanisms discussed in this paper, but also via indirect effects due to the different response of the autoconversion parametrizations to aerosol and cloud droplet number.

Acknowledgements. We would like to thank Casey Burleyson for provision of the C-band radar data, and Ken Moran and Chris Fairall for the W-band radar data. The Facility for Airborne Atmospheric Measurements (FAAM) are thanked for the BAe-146 data. GOES-10, Ronald H. Brown and NSF/NCAR C-130 datasets were obtained from the NCAR/EOL data archive. AMSR-E, SSMI and TMI data are produced by Remote Sensing Systems and sponsored by the NASA Earth Science MEaSUREs DISCOVER Project and the AMSR-E Science Team. The microwave radiometer was on loan from Peter Minnett, and we thank Stuart Webster for his help setting up the nested suite of simulations.

Edited by: R. Wood

\section{References}

Abel, S. J. and Boutle, I. A.: An improved representation of the rain drop size distribution for single-moment microphysics schemes, Q. J. Roy. Meteor. Soc., in press, 2012.

Abel, S. J., Walters, D. N., and Allen, G.: Evaluation of stratocumulus cloud prediction in the Met Office forecast model during VOCALS-REx, Atmos. Chem. Phys., 10, 10541-10559, doi:10.5194/acp-10-10541-2010, 2010.

Allen, G., Coe, H., Clarke, A., Bretherton, C., Wood, R., Abel, S. J., Barrett, P., Brown, P., George, R., Freitag, S., McNaughton, C., Howell, S., Shank, L., Kapustin, V., Brekhovskikh, V., Kleinman, L., Lee, Y.-N., Springston, S., Toniazzo, T., Krejci, R., Fochesatto, J., Shaw, G., Krecl, P., Brooks, B., McMeeking, G., Bower, K. N., Williams, P. I., Crosier, J., Crawford, I., Connolly, P., Allan, J. D., Covert, D., Bandy, A. R., Russell, L. M., Trembath, J., Bart, M., McQuaid, J. B., Wang, J., and Chand, D.: South East Pacific atmospheric composition and variability sampled along $20^{\circ} \mathrm{S}$ during VOCALS-REx, Atmos. Chem. Phys., 11, 5237-5262, doi:10.5194/acp-11-5237-2011, 2011.

Andrejczuk, M., Grabowski, W. W., Gadian, A., and Burton, R.: Limited-area modelling of stratocumulus over South-Eastern Pacific, Atmos. Chem. Phys. Discuss., 11, 25517-25556, doi:10.5194/acpd-11-25517-2011, 2011.

Bodas-Salcedo, A., Webb, M. J., Brooks, M. E., Ringer, M. A., Williams, K. D., Milton, S. F., and Wilson, D. R.: Evaluating cloud systems in the Met Office global forecast model using simulated CloudSat radar reflectivities, J. Geophys. Res., 113, D00A13, doi:10.1029/2007JD009620, 2008.

Bodas-Salcedo, A., Webb, M. J., Bony, S., Chepfer, H., Dufresne, J.-L., Klein, S. A., Zhang, Y., Marchand, R., Haynes, J. M., Pincus, R., and John, V. O.: COSP: satellite simulation software for model assessment, B. Am. Meteorol. Soc., 92, 1023-1043, doi:10.1175/2011BAMS2856.1, 2011.

Bony, S. and Dufresne, J.-L.: Marine boundary layer clouds at the heart of tropical cloud feedback uncertainties in climate models, Geophys. Res. Lett., 32, L20806, doi:10.1029/2005GL023851, 2005.

Boutle, I. A. and Morcrette, C. J.: Parametrization of area cloud fraction, Atmos. Sci. Lett., 11, 283-289, 2010.

Comstock, K. K., Wood, R., Yuter, S. E., and Bretherton, C. S.: Reflectivity and rain rate in and below drizzling stratocumulus, Q. J. Roy. Meteor. Soc., 130, 1801-1816, 2004.

Edwards, J. M. and Slingo, A.: Studies with a flexible new radiation code. I: Choosing a configuration for a large-scale model, Q. J. Roy. Meteor. Soc., 122, 689-719, 1996.

Gregory, D. and Rowntree, P. R.: A mass flux convection scheme with representation of cloud ensemble characteristics and stability-dependent closure, Mon. Weather Rev., 118, 14831506, 1990.

Jones, C. R., Bretherton, C. S., and Leon, D.: Coupled vs. decoupled boundary layers in VOCALS-REx, Atmos. Chem. Phys., 11, 7143-7153, doi:10.5194/acp-11-7143-2011, 2011.

Khairoutdinov, M. and Kogan, Y.: A new cloud physics parameterization in a large-eddy simulation model of marine stratocumulus, Mon. Weather Rev., 128, 229-243, 2000.

Lean, H. W., Clark, P. A., Dixon, M., Roberts, N. M., Fitch, A., Forbes, R., and Halliwell, C.: Characteristics of high-resolution versions of the Met Office Unified Model for forecasting convection over the UK, Mon. Weather Rev., 136, 3408-3424, 2008. 
Lock, A. P., Brown, A. R., Bush, M. R., Martin, G. M., and Smith, R. N. B.: A new boundary layer mixing scheme. Part I: Scheme description and single-column model tests, Mon. Weather Rev., 128, 3187-3199, 2000.

Marshall, J. S. and Palmer, W. M.: The distribution of raindrops with size, J. Meteorol., 5, 165-166, 1948.

McCaa, J. R. and Bretherton, C. S.: A new parameterization for shallow cumulus convection and its application to marine subtropical cloud-topped boundary layers. Part II: Regional simulations of marine boundary layer clouds, Mon. Weather Rev., 132, 883-896, 2004.

Nicholls, S.: The dynamics of stratocumulus: aircraft observations and comparisons with a mixed layer model, Q. J. Roy. Meteor. Soc., 110, 783-820, 1984.

Siebesma, A. P., Jakob, C., Lenderink, G., Neggers, R. A. J., Teixeira, J., Meijgaard, E. V., Calvo, J., Chlond, A., Grenier, H., Jones, C., Köhler, M., Kitagawa, H., Marquet, P., Lock, A. P., Müller, F., Olmeda, D., and Severijns, C.: Cloud representation in general-circulation models over the Northern Pacific Ocean: a EUROCS intercomparison study, Q. J. Roy. Meteor. Soc., 116, 3245-3267, 2004.

Slingo, A.: Sensitivity of the earth's radiation budget to changes in low clouds, Nature, 343, 49-51, 1990.

Smagorinsky, J.: General circulation experiments with the primitive equations. Part 1: the basic experiment, Mon. Weather Rev., 91, 99-164, 1963.

Smith, R. N. B.: A scheme for predicting layer clouds and their water content in a general circulation model, Q. J. Roy. Meteor. Soc., 116, 435-460, 1990.

Stephens, G. L., L'Ecuyer, T., Forbes, R., Gettlemen, A., Golaz, J.C., Bodas-Salcedo, A., Suzuki, K., Gabriel, P., and Haynes, J.: Dreary state of precipitation in global models, J. Geophys. Res., 115, D24211, doi:10.1029/2010JD014532, 2010.

Tripoli, G. J. and Cotton, W. R.: A numerical investigation of several factors contributing to the observed variable intensity of deep convection over South Florida., J. Appl. Meteorol., 19, 10371063, 1980.

Twomey, S.: Pollution and the planetary albedo, Atmos. Eviron., 8, 1251-1256, 1974.

Walters, D. N., Best, M. J., Bushell, A. C., Copsey, D., Edwards, J. M., Falloon, P. D., Harris, C. M., Lock, A. P., Manners, J. C., Morcrette, C. J., Roberts, M. J., Stratton, R. A., Webster, S., Wilkinson, J. M., Willett, M. R., Boutle, I. A., Earnshaw, P. D., Hill, P. G., MacLachlan, C., Martin, G. M., Moufouma-Okia, W., Palmer, M. D., Petch, J. C., Rooney, G. G., Scaife, A. A., and Williams, K. D.: The Met Office Unified Model Global Atmosphere 3.0/3.1 and JULES Global Land 3.0/3.1 configurations, Geosci. Model Dev., 4, 919-941, doi:10.5194/gmd-4-919-2011, 2011.
Wang, S., O’Neill, L. W., Jiang, Q., de Szoeke, S. P., Hong, X., Jin, H., Thompson, W. T., and Zheng, X.: A regional real-time forecast of marine boundary layers during VOCALS-REx, Atmos. Chem. Phys., 11, 421-437, doi:10.5194/acp-11-421-2011, 2011.

Wilkinson, J. M., Porson, A. N. F., Bornemann, F. J., Weeks, M., Field, P. R., and Lock, A. P.: Improved microphysical parametrization of drizzle and fog for operational forecasting using the Met Office Unified Model, Q. J. Roy. Meteor. Soc., in review, 2012.

Wilson, D. R. and Ballard, S. P.: A microphysically based precipitation scheme for the Meteorological Office Unified Model, Q. J. Roy. Meteor. Soc., 125, 1607-1636, 1999.

Wilson, D. R., Bushell, A. C., Kerr-Munslow, A. M., Price, J. D., and Morcrette, C. J.: PC2: a prognostic cloud fraction and condensation scheme. I: Scheme description, Q. J. Roy. Meteor. Soc., 134, 2093-2107, 2008.

Wood, R.: Drizzle in stratiform boundary layer clouds. Part II: Microphysical aspects, J. Atmos. Sci., 62, 3034-3050, 2005.

Wood, R., Mechoso, C. R., Bretherton, C. S., Weller, R. A., Huebert, B., Straneo, F., Albrecht, B. A., Coe, H., Allen, G., Vaughan, G., Daum, P., Fairall, C., Chand, D., Gallardo Klenner, L., Garreaud, R., Grados, C., Covert, D. S., Bates, T. S., Krejci, R., Russell, L. M., de Szoeke, S., Brewer, A., Yuter, S. E., Springston, S. R., Chaigneau, A., Toniazzo, T., Minnis, P., Palikonda, R., Abel, S. J., Brown, W. O. J., Williams, S., Fochesatto, J., Brioude, J., and Bower, K. N.: The VAMOS Ocean-Cloud-Atmosphere-Land Study Regional Experiment (VOCALS-REx): goals, platforms, and field operations, Atmos. Chem. Phys., 11, 627-654, doi:10.5194/acp-11-6272011, 2011.

Wyant, M. C., Wood, R., Bretherton, C. S., Mechoso, C. R., Bacmeister, J., Balmaseda, M. A., Barrett, B., Codron, F., Earnshaw, P., Fast, J., Hannay, C., Kaiser, J. W., Kitagawa, H., Klein, S. A., Köhler, M., Manganello, J., Pan, H.-L., Sun, F., Wang, S., and Wang, Y.: The PreVOCA experiment: modeling the lower troposphere in the Southeast Pacific, Atmos. Chem. Phys., 10, 4757-4774, doi:10.5194/acp-10-4757-2010, 2010.

Zuidema, P., Westwater, E., Fairall, C., and Hazen, D.: Ship-based Liquid Water Path Estimates in Marine Stratocumulus, J. Geophys. Res., 110, D20206, doi:10.1029/2005JD005833, 2005. 